\title{
nature
}

\section{Prize-winning multidisciplinarity}

The winner of a new prize exemplifies outstanding scientific breadth. But crossing boundaries brings challenges of its own, and progress in meeting them has been mixed.

$\mathrm{T}$ he world is full of scientific prizes, provided bylearned societies, industry, philanthropists and governments: some with big money attached, some tiny but equally prestigious, some that aim to elevate, others to ridicule.

It's welcome, therefore, that a new annual prize not only celebrates scientific excellence but can be bestowed for whatever additional positive criterion its judges choose. Earlier this year, the Kohn Foundation gave to the Royal Institution of Great Britain funds for an annual prize of $£ 10,000$, to be called the Henry Dale prize (named after the neurophysiologist and Nobel laureate who directed the Royal Institution's laboratories). It is to be awarded annually to a life scientist who has worked in, or engaged with, the United Kingdom.

This year the committee (of which Nature's editor is a member) decided to invite nominations of scientists who, as the additional criterion, had made outstanding multidisciplinary contributions. Individuals who single-handedly embody multidisciplinary ideals are rare, after all.

As the entries showed, new techniques in physics, chemistry and mathematics, or old techniques applied in new ways to biological problems, provide opportunities for significant individual achievement. So too do combinations of clinical, epidemiological and basic biological research into conditions and disease.

It helps a candidate's case when the problem tackled is a fundamental one, when striking solutions have been found, and when they have applications in industry and implications for society. And above all it helps if the researcher has spanned the spectrum of scientific practice; has produced an interesting hypothesis that connects fundamental processes with evolutionary considerations and makes specific predictions; and then spends three decades pursuing its implications using mathematical modelling, experiment and evolutionary studies to demonstrate the power of that hypothesis.

This sums up of the career so far of this year's winner of the Henry Dale prize: Tom Kirkwood, head of the Department of Gerontology at the University of Newcastle upon Tyne. And as Nature exists above all to promote communication across the disciplines, it seems appropriate to highlight such multidisciplinary science in action, as well as to point to its associated challenges.

It was a chance conversation in a lift with a researcher in ageing, Robin Holliday, that first set Kirkwood's mind on to the problem. A mathematician-turned-biologist, Kirkwood developed an idea that ageing is the result not of a pre-programmed set of biological events, but of an accumulation of damage that occurs because natural selection did not place a high priority on long-term cellular repair. According to this notion, evolution has delivered a trade-off in the use of resources between maintaining the quality of the organism and reproducing it - in favour of the latter. This is one of several current theories of ageing (see Nature 408, 233; 2000), but since its publication in 1977 it has provided a rich seam of predictions and experimental tests, yielding insights of their own and leaving the hypothesis unscathed.

Inevitably, people studying a mechanism associated with ageing, such as telomere shortening or oxidative stress, focus on their own territory and may underestimate the importance of the combined effects of both. But Kirkwood has pursued modelling techniques that allow synergies between different influences to be investigated. He now looks forward to a greater emphasis on analysing both predictable and stochastic cellular behaviours of organisms in late age, made possible by advances in computation and experimental techniques.

Kirkwood knows as well as anyone the difficulties that can confront multidisciplinary research. Funding agencies now cope quite well in crossing disciplinary boundaries. But he has also seen difficulties in journals' peer-review processes when, as he puts it, a referee can see bridges being built from opposite sides of a disciplinary chasm but cannot judge where they should meet. He is not alone in his caution about institutions that draw together scientists from different disciplines in the hope that sparks will fly - mental proximity counts more than physical. But how to ensure that researchers working in more than one discipline, who have to be employed within one disciplinary department while collaborating with another, will not be seen as foreign by both when it comes to institutional recognition and promotion? This challenge is now more important to address than ever.

\section{Committed, yes. And commitments?}

\section{Tony Blair's speech to the Royal Society last week was an important act of leadership. Now what?}

$\mathrm{B}$ ritain is a crucible for technological inventiveness and scientific creativity, and some of its industries know how to profit from it. Yet it has provided some dreadful examples of the interplay of science, media and the public in addressing controversial technologies. So it matters to sometimes-beleaguered researchers and technologists when its prime minister celebrates science as a key national activity and positions himself firmly in its favour against what he characterizes as the timidity that overshadows public debates. Such public angst is notorious enough, he said last week, for industrialists in Bangalore to tell him that they would leapfrog British technology because of it. (A full text of the speech is at www.nature.com/nature/blair.html)

Tony Blair's speech may herald a renewed government campaign in support of commercialization of genetically modified crops and animal experimentation, and comes ahead of the outcome of a review of public spending, due in the summer. Researchers should applaud Blair for his sustained support, and reiterate their wish-list for public funds, but with higher expectations. More money for science teachers and facilities in schools, rebuilding of university infrastructure, further improvements to pay and conditions for postdocs, ensuring that government and its agencies can commission independent research to sustain regulatory standards, and enhancing the resources available to independent agencies for providing public information and conducting public consultation in topics of significant social concern - such commitments are priorities if Blair's committed rhetoric is to yield substance. 